Uşak Üniversitesi Sosyal Bilimler Dergisi

2014, 7(1), 24-37

\title{
Elektronik Ödeme Sistemlerinin Karşılaştırılması: Türkiye ve İtalya Örneği
}

Selim DURAMAZ*

Sabri DÜNDAR

Özet

Teknoloji kullanımının gün geçtikçe artması sonucu bankaların ürün ve hizmet çeşitliliği artmıştır. Bununla birlikte elektronik ödeme araçlarının da farklı türleri ortaya çıkmıştır. Günümüzde bireyler ve kurumlar elektronik ödeme araçlarını kullanarak yatırım ve finansal işlemlerini kolaylıkla gerçekleştirmektedirler. Çalışmada $\mathrm{AB}$ üyesi olma yolunda ilerleyen Türkiye'de ve bir AB ülkesi olan İtalya'da elektronik ödeme araçlarının geçmişi ve bugünü incelenmiş ve karşılaştırılmıştır. Çalışmanın sonucunda; günümüzde en yaygın olarak kullanılan kartlı ödeme sistemleri ile Türkiye'de İtalya'ya göre daha fazla harcama yapıldığına ulaşılmıştır. Aynı şekilde internetten yapılan ödemelerdeki artış hızı Türkiye'de yüzde 50 iken İtalya' da yüzde $18^{\prime}$ dir.

Anahtar Kelimeler: Elektronik Ödeme Sistemleri, Ödeme Araçları, İtalya, Türkiye.

\section{A Comparison of Electronic Payment Systems:} The Case of Turkey and Italy

\footnotetext{
Abstract

As a result of growing the use of technology, variety of banks products and services has been increased. However, different types of electronic payment instruments have emerged. Today, by using of electronic payment instruments, people and institutions have done investment and financial transactions easily. In the study, past and today of electronic payment instruments which are being used in Turkey (which is an applicant for European Union) and Italy (which is an initiate of European Union) are examined and compared. By using card payment systems which are being used commonly in today, there is more spending in Turkey to Italy. Similarly, growth rate of payments which made from internet in Turkey is 50 percent and in Italy is 18 percent.

Key Words: Electronic Payment Systems, Payment Instruments, Italy, Turkey.

"Arş. Gör., Celal Bayar Üniversitesi Uygulamalı Bilimler Yüksekokulu Bankacılık ve Finans Bölümü

"* Bilim Uzmanı,Celal Bayar Üniversitesi Akhisar Meslek Yüksek Okulu
} 
Sosyal Bilimler Dergisi 25

\section{Giriş}

Son 20 ylllık süreçte nakit ödeme yerine nakit olmayan ödeme sistemlerinin kullanımında önemli bir miktarda artış yaşanmıştır. Tüketicilerin, ödemelerinde otomatik ve elektronik ödeme araçlarını kullanması da bu yönde artmıştır. İnternet bankacılığı ve de internetten alışverişin artması tüketicilere zaman ve mekan sınırı olmadan ödeme yapmasına olanak sağlamıştır (European Central Bank, 2010:33).

Ödeme araçları kaynağın ödeyiciden alacaklıya transferine imkan veren bir araç ya da süreç olarak tanımlanır. Ödeyici ve alacaklı arasındaki işlem ve ilişkinin türüne bağlı olarak farklı özellikler taşıyan farklı ödeme araçları söz konusudur. Bunlardan en yaygın olanı da nakit ve nakit olmayan ödeme araçlarıdır (ECB, 2010:28). Nakit ödeme aracı borcun nakit olarak ödenerek bedeli karşılığında anında mal ve hizmet satın alınabilinmesi olarak geçmişten günümüze uzanan geleneksel bir ödeme sistemi aracı iken bununla birlikte günümüzde elektronik ödeme sistemleri de sıkça kullanılan ve tercih edilen bir yöntem haline gelmiştir.

Çalışmada öncelikle elektronik ödeme sistemi araçlarının Türkiye'deki kullanım geçmişi verilerek günümüzdeki kullanım rakamları ve kullanım yerleri tanımlanacaktır. Devamında ise elektronik ödeme araçlarının İtalya'daki geçmişi ve rakamlarla ilgili veriler sunulacaktır. Çalışmanın sonucunda da bu iki ülkeye ait veriler karşılaştııılarak yorumlanacaktır.

\section{Elektronik Ödeme Sistemleri}

Ödeme sistemleri, ekonomik birimlerin arasında gerçekleşen mal ve hizmetlerin değişimlerini daha kolay hale getiren araçları, kurumsal ve örgütsel çatıyı, işletim süreçlerini ve de haberleşme ağının tümünü kapsamaktadır. Zamanla mali sistemin içerisindeki finansal risklere, güvenilirliğe ve de hılılığa yönelik reformlar sonrasında ödeme sistemlerinde büyük değişimler yaşanmıştır ve yaşanmaktadır (Türkiye Cumhuriyet Merkez Bankası, 2013a).

Günümüzde elektronik ödeme sistemlerinin gelişmesiyle elektronik ödeme araçları yardımıyla bankalara verilen talimatlar veya online sistemler üzerinden bireyler ve kurumlar kendileri fon, menkul kıymet transferleri vb. değerleri kolaylıkla satın alabilmekte ve transfer edebilmektedir. Elektronik ödeme sistemleri, elektronik fon transferi (EFT), kredi kartları, akıllı (smart) kartlar, borç kartları gibi mal ve hizmetlerin karşılığını otomatik olarak ödeyen veya kayitlara geçiren temelinde internet olan teknolojilerdir (Özmen, 2012:311). 


\section{A. Türkiye'de Elektronik Ödeme Sistemleri}

Ülkemizde ödeme sistemlerinden Türkiye Cumhuriyet Merkez Bankası (TCMB) sorumlu olmakla birlikte, TCMB'nin hedef ve politikaları 25.4.2001 tarih 4651 sayılı kanun ile 1211 sayılı TCMB Kanunu madde 4-I-f ile uyumlu olarak belirlenmiştir. Buna göre TCMB, kurulmuş ve kurulacak olan ödeme sistemlerinin güvenli, kesintisiz, etkin işleyişini sağlayacak ve sistemlerin içerebilecekleri riskleri azaltacak düzenlemeleri yapmak, finansal ve parasal istikrarın sağlanması için, para politikalarının etkin bir şekilde yürütülmesi amacıyla ödeme sistemlerinde günün koşullarına göre gerekli düzenlemeleri yapmak, sistemlerin etkinliğini ve güvenliğini etkileyebilecek gelişmeleri takip etmek gibi yetki ve görevlerle donatılmıştır (TCMB, 2013b).

\section{Kredi Kartı}

Kredi kartları, belli limitler dahilinde nakite ihtiyaç duyulmadan mal ve hizmet alımına ve aynı zamanda nakit çekimine imkan veren ödeme araçlarıdır. Kredi kartı kullanıcısına para taşıma zorunluluğunu ortadan kaldırmaktadır ve bununla birlikte üye işyerlerinde cirolarını arttırabilme olanağı sağlaması gibi özellikleri nedeniyle kullanımı gün geçtikçe artmıştır. Böylelikle kredi kartları, alıcı ve satıcılar arasındaki mal ve hizmet ilişkilerinde, güvenilir, hızlı ve de etkin bir ödeme aracına duyulan gereksinimlerden ortaya çıkmıştır (Kirdaban, 2005:12).

Türkiye'de kredi kartlarının ilk temsilcisi Koç Grubu'na bağlı "Servis Turistik AŞ." olmuştur. Firma, Amerika Birleşik Devletleri (ABD)'nden yurtiçi kart çıkarma yetkisini almış ve 1968 yılında "Diners Club" kredi kartlarını sunmaya başlamıştır. Daha sonra ise Türk Ekspres Havacılık ve Turizm Ltd. Şti "Amerikan Ekspres" kartları ile piyasaya girmiştir. 1975'e gelindiğinde ise Interbank grubuna bağlı Eurocard, Mastercard ve Access kredi kartları piyasaya girmiştir. Bu üçlü grup daha sonra birleşerek yetkilerini "Anadolu Kredi Kartları Turizm AŞ.'ye devretmiştir. 1980 yılından sonra ise kredi kartlarının piyasada gördüğü ilgi ve aynı zamanda karlılık nedeniyle bankalar da kredi kartı uygulamasına geçmişlerdir. Gerek Mastercard gerekse Visa kredi kartlarının büyük bankalar tarafından çıkarılması ve hızla yayılması, anlaşmalı işyerlerinin gün geçtikçe artması sonucu kredi kartı sistemi ülkemizde hızlı bir gelişme göstermeye başlamıştır (Bankalararası Kart Merkezi, 1997:1).

1990 yılında ise Bankalararası Kart Merkezi faaliyete geçmiştir. 13 kamu ve özel Türk bankasının ortaklığıyla kurulan Bankalararası Kart Merkezi'nin (BKM) faaliyetleri, ödeme sistemleri içerisinde; nakit kullanımı gerekmeksizin her türlü ödemeyi veya para transferini sağlayan veya destekleyen, sistem, platform ve altyapıları oluşturmak, işletmek ve aynı 
zamanda geliştirmektir. Bununla birlikte BKM'nin ana faaliyetleri arasında kredi kartı ve banka kartı uygulaması içinde bulunan bankalar arasında uygulanacak prosedürleri geliştirmek, standardizasyonu sağlamaya yönünde çalışmalar yapma, Türkiye genelinde uygulamalar ile yurtiçi kuralları oluşturmak, bankalar arasındaki takas ve hesaplaşmayı yürütmek, yurtdışı kuruluş ve komisyonlarla ilişkiler kurmak, bankalar tarafından devam ettirilen işlemleri daha güvenli, süratli ve maliyeti daha az olarak tek bir merkezden yürütmek sayılabilir (BKM, 2012a).

Aşağıdaki şekilde kredi kartı ile yapılan alışverişlerde gerçekleşen ödeme akışı ve ilgili taraflar bulunmaktadır. İlgili taraflar; müşteri, satıcı, bankalar ve aracı kurumlardır. Bankalararası Kart Merkezi, Visa ve Mastercard'ın dünya çapında gerçekleştirdiği işlemlerin benzerlerini Türkiye'de ulusal bazda gerçekleştirmek amacıyla Türkiye'deki bankaların bir araya gelerek kurduğu bir kuruluştur. Türkiye'de yerel işlemlerde BKM ağları, uluslararası işlemlerde ise VISA ve Mastercard ağları kullanılmaktadır. Ancak bazı bankalar, BKM ağlarını kullanmadan da doğrudan uluslararası ağlara da erişebilmektedir (Özmen, 2012:472).

\section{Şekil 1: Kredi Kartı Ödeme Akışı}

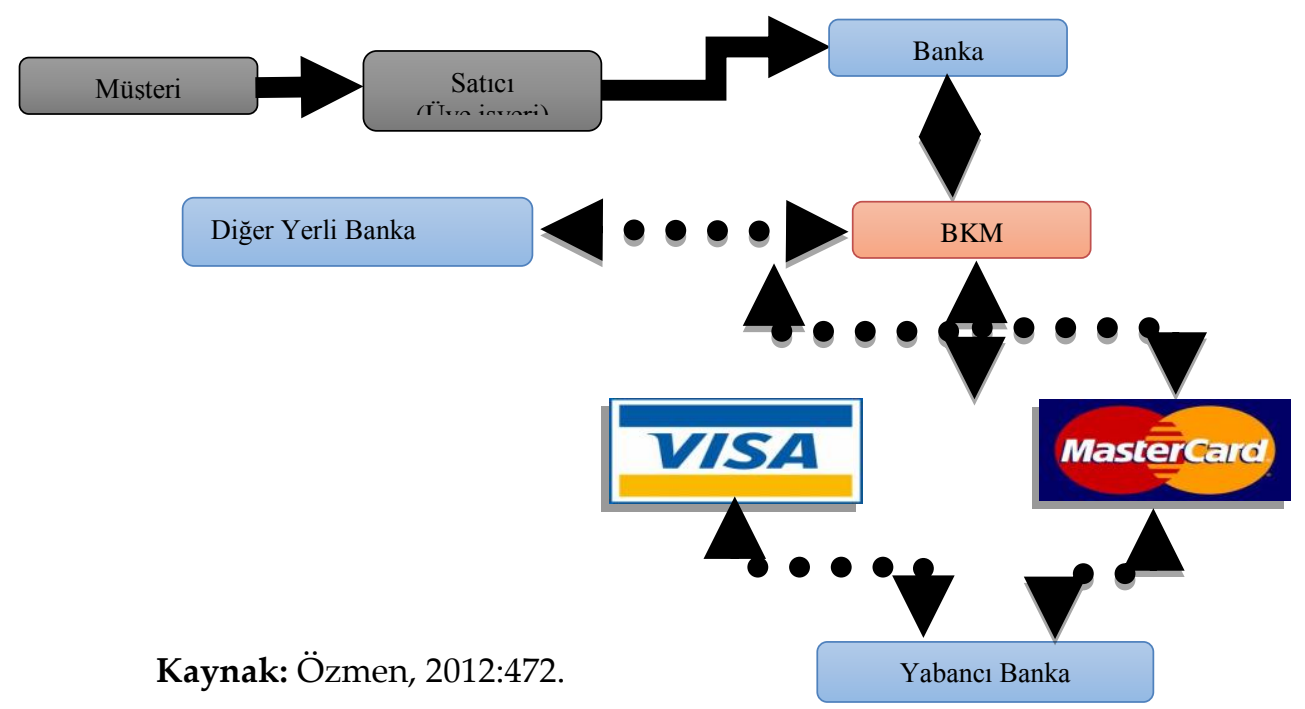

Bankalararası Kart Merkezi tarafından her yıl yaptırılan Kart Monitör araştırmasının 2012 sonuçlarına bakıldığında, Türkiye'de bundan sadece 5 yıl öncesinde kredi kartı sayısı 32-33 milyon aralığında iken, bugün bu rakam yüzde 65'lik bir artışla 53 milyonu aşmış durumdadır. Türkiye'de 2012 yılında Türkiye'de POS (Point of Sale) sayısı da 2 milyonun üzerine 
çıkarken, ATM'ler (Automatic Teller Machine) sayısı ise 35 binin üzerindedir. 2007 yılından 2012 yılına kadar POS sayısı yüzde 65, ATM sayısı ise yüzde 112 oranında artmıştır (BKM, 2012c:9). Yine BKM istatistiklerine bakıldığında alışveriş ve nakit çekim işlemi olarak kredi kartlarıyla 2011 yılında Türkiye'de toplam 285,2 milyar TL'lik (yaklaşık 122,4 milyar euro) işlem hacmi ortaya çıkmıştır (BKM, 2012b).

\section{Internet}

Online ödeme, hizmet ödemeleri yapma, fon aktarımı ve çevrimiçi alışveriş yapma gibi çeşitli amaçlar için ödeme yapmanın hızlı ve güvenilir bir yoludur. Mal ve hizmetlerin nakit karşılı̆̆ında alınmasının yanında online olarak da günümüzde kolaylıkla satın alınabilmektedir. Bu anlamda online ödeme portalları, hayatımızı basitleştiren güçlü bir araç olmakla birlikte, bulunduğumuz mekandan ayrılmadan dünyanın herhangi bir yerinde istenilen tüm ödeme işlemlerini gerçekleştirmemize imkan verir. Ödemenizi birkaç saniye içinde gerçekleştirmekle birlikte ödeyiciye, ödeme sürecinde ödeme işlemleri için iyi tanımlanmış birçok süreci içerir. Günümüzde neredeyse tüm ürünler online ödeme yoluyla satın alınabilmektedir. Alıcılar, satın alacakları ürünün resmini ya da videosunu görebilmekte ve hızlı bir şekilde karar verebilmektedir. Kullanıcılar tüm ürünler için ödemelerini kredi kartı, banka kartı, mevduat hesabı gibi araçlarla ödemelerini gerçekleştirebilmektedir (Nagasubramanian and Rajagopalan, 2012:35).

Ülkemizde internet bankacıllğı yapmak üzere sistemde kayıtlı olan ve en az bir kez giriş işlemi yapmış toplam bireysel müşteri sayısı, Aralık 2011 itibariyle, 18,1 milyon kişidir. Yine internet bankacılığı kullanılarak yapılan işlemlerin tutarı da 2011 yılı içerisinde toplam 1.551 .062 milyon TL"'dir (Türkiye Bankalar Birliği, 2012). Yine Kart Monitör dergisine göre İnternetten yapılan kartlı ödemelerde Avrupa ülkeleriyle bir karşılaştırma yapıldığında, Türkiye'nin büyüme grafiği \% 50'yi bulmaktadır (BKM, 2012c:13).

\section{Elektronik Fon Transferi (EFT)}

Bankacılık sektörü ve bilişim teknolojisindeki gelişmeler, bankalararası işlemlerin hacim ve aynı zamanda tutarının büyük miktarda artması, elektronik bankacılık hizmetlerinin yaygınlaşması ülke çapında elektronik bankacilık altyapısının kurulmasını ve de bankalararası elektronik fon transferi sisteminin varlığını gündeme getirmiştir. Türkiye

\footnotetext{
* Türkiye Bankalar Birliği internet sitesinde ilan edilen 3'er aylık internet istatistik verilerinin toplamı sonucu yıllık toplam tutar elde edilmiştir.
} 
Sosyal Bilimler Dergisi 29

Cumhuriyet Merkez Bankası (TCMB), bu tür sistemlerin ülke ekonomileri üzerindeki olumlu etkilerini de göz önüne alarak bir ödeme sistemi kurmayı bankacılık sektörü için gerekli görerek; Ekim 1989'da başlattığı çalışmalarını tamamlamış ve EFT Sistemini Nisan 1992'de işletime açmıştır (TCMB, 2006:1).

Elektronik Fon Transfer Sistemi Türk Lirası ödeme işlemlerinin, Elektronik Menkul Kıymet Transfer (EMKT) Sistemi ise menkul kıymet transferlerinin bankalar arasında elektronik ortamda ve de gerçek zamanlı olarak yapılmasını ve mutabakatını sağlayan sistemlerdir (TCMB, 2006:1).

Şekil 2: EFT-EMKT Sistemi

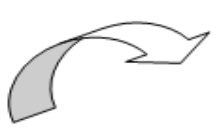

A BANRASI

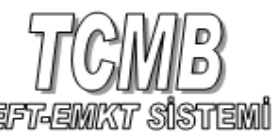

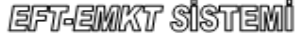

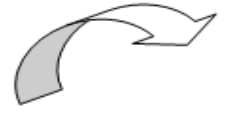

B BANRLASL

Kaynak: TCMB, 2012a.

Şekilde görüldüğü gibi herhangi bir bankadan verilen EFT-EMKT ödeme emri öncelikle Merkez Bankası'na düşmektedir. Daha sonra ise tutar diğer bankaya aktarılmaktadır. EFT-EMKT sisteminden geçen tutar 2011 yılında iken 39.311 milyar TL iken 2012 yılındaki tutar 32.703 milyar TL olmuştur (TCMB, 2012b).

\section{Akıllı (Smart) Kart- Elektronik Para}

Kredi kartları manyetik bantlı kartlar olarak işlem görmekteyken, elektronik para aracı olarak nitelendirilebilecek akıllı kartlar ise içerisinde gömülü bir mikroçiplerin bulunduğu bir sistemdir. Mikroçipin içinde kredi kartlarından yani manyetik bantlı kartlardan farklı olarak daha fazla elektronik bilgi ve programlar depo edilir ve de akıllı kartlarda saklanabilinen bilgi hafızası 80 kat daha fazladır. Bununla birlikte ayn zamanda kart üzerinde basit uygulamalar da tutulabilmektedir ve kartlar bu özelliğiyle küçük bir bilgisayar vazifesi görebilirler. Akıllı kartlar üzerinde kart sahibinin kredi kartı bilgileri ve vadesiz hesap bilgileriyle beraber nakit parası da tutulabilir. Müşteri, ATM ya da başka bir kanal aracılığıyla kart üzerinde nakit bittikçe, kartı hesabındaki para ile doldurabilir (BKM, 2000:2).

Türkiye'deki uygulamalara bakıldığında elektronik paranın kredi kartı benzeri plastik kartların üzerindeki çiplere yüklenmesi ve de bu kartların üye iş yerlerinde kullanılması yöntemi çok fazla kullanılmamakla 
birlikte (Karpuz, 2012:151) yeni yeni gelişmektedir. Akıllı kart olarak nitelendirilebilecek bu uygulamalarda kartla harcama yapılabilmesi için akıllı kart sistemleri ile anlaşmalı merkezlerin ve üye işyerlerinin varlığ gerekmektedir. Bu anlamda Multinet, Sodexho gibi uygulamalar ülkemizdeki akıllı kart uygulamaları arasında gösterilebilir.

Türkiye'deki bankalar incelendiğinde ülkemizde akıllı kart uygulamasını Vakıfbank ve İş Bankası gerçekleştirmektedir. Bu bankalar, akıllı kartları ulaşım ve üniversite uygulamalarında hizmete sunmaktadır. Buna yönelik olarak İşbankası'nın akıllı kart uygulaması incelendiğinde, ulaşım uygulamaları için Kocaeli BŞB ve üniversite uygulamaları için ise Orta Doğu Teknik Üniversitesi, Kocaeli ve Yıldız Teknik Üniversitesi ile işbirliği yapmıştır. Böylelikle kişinin İşbankası cari hesabı veya İşbankası kredi kartı ile ilişkilendirilen akıllı karta para yüklenilerek ulaşımda veya üniversite kampuslerinde kafeterya, kütüphane, havuz vb. aktivite ve imkanlardan yararlanılabilinmektedir (İşbankası, 2012).

Bununla birlikte akıllı kart ülkemizde bankaların dışında belediyeler tarafından taşımacılıkta ve diğer belediye hizmetlerinde uygulanmaktadır. Ancak bu kartlara sadece belirli noktalardan para yüklenilmekte, herhangi bir banka hesabıyla veya kredi kartıyla bağlantı kurulmamaktadır.

\section{Diğerleri}

Temassız Ödeme Araçları: Temassız ödeme aracı; kredi kartı veya banka kartı gibi diğer ödeme kartlarının üye iş yerlerinde kullanılırken POS cihazı gibi herhangi bir araçla temas etmeden kullanılan bir araçtır. Bu yöntem ülkemizde kartlı ödeme sistemleri konusunda öncü birkaç banka tarafından pazarlanmaya başlamıştır. Anılan hizmet kapsamında, gerekli altyapıya sahip iş yerlerinde kredi kartını POS cihazına okutmadan, sadece temassız kredi kartının takılı olduğu cep telefonu veya saat gibi bir aracı ilgili cihaza 3-4 cm. yanaştırarak ödeme işlemi gerçekleştirilmektedir (Karpuz, 2012:157).

Ülkemizde temassız ödeme aracı hizmetini birçok banka sunmaktadır. Buna göre kredi kartlarına yüklenilen ekstra bir özellikle veya için yeni bir kartla ülkemizde genellikle $35 \mathrm{TL}$ altı işlemler temassız olarak gerçekleştirilebilmektedir.

BKM Ekspress: BKM Express, internet üzerinden alışverişlerde müşterilerin kart bilgisini işyerleri ile paylaşmadan işlem yapabilmesini sağlayan bir ödeme sistemidir. Öncelikle BKM ekspress sistemine üye olunması ve sadece bir kez kart bilgilerinin girilmesi ile internetten, BKM Ekspress sistemi üzerinden alışveriş yapılabilmektedir. Böylelikle internetten yapılan alışverişlerde her defasında kart bilgilerinin ekrana 
Sosyal Bilimler Dergisi 31

girilmesine gerek kalmayacaktır. Ülkemizde şu an BKM ekspres uygulamasını Akbank, Bank Asya, Finansbank, Garanti Bankası, ING Bank, TEB, Türkiye İş Bankası, Vakıfbank, Yapı Kredi, Ziraat Bankası uygulamaktadır (BKM Ekspress, 2013). BKM Ekspress sistemi yurtdışında yaygın olarak kullanılan Paypal sisteminin ülkemizdeki örneği olarak belirtilebilir. Paypal yurtdışının yanı sıra Türkiye'de de BKM Ekspress ile aynı nitelikte hizmeti ülkemizde de sunmaya başlamıştır.

Mobil Ödeme: Mobil ödeme sistemi alışveriş sırasında cep telefonunuza gelen mesajı veya cep telefonu numaranızı cep telefonu operatörlerinin anlaşmalı üye yerine vermeniz neticesinde, yaptığınız alışverişin cep telefonu faturanıza yansıması veya lira bakiyenizden düşmesi sonucu gerçekleşen ödeme aracıdır. Ülkemizdeki operatörler bu hizmeti yeni yeni sunmaya başlamıştır.

\section{B. İtalya'da Elektronik Ödeme Sistemleri}

İtalya'da ödemeler sisteminin etkili ve güvenilir bir şekilde işlemesinden İtalya Merkez Bankası sorumludur (Bank For International Settlements (BIS), 2012:242). Bu anlamda Merkez Bankası'nın yetkileri kanunla güvence altındadır. İtalya'da düzenleyici ve yasayıcı önlemlerin alınması hedefine yönelik (i) yeni ödeme araçlarının kullanımının teşvik edilmesi, (ii) ödeme sistemlerinde güvenilirliğin güçlendirilmesi, (iii) İtalyan mevzuatını Avrupa Birliği yönetmeliklerine uyumu ile kurumsal yapıda önemli değiş̧iklikler gerçekleşmiştir. Bu tür düzenlemeler ödeme sistemleri ile ilgili altyapı ve ödeme araçları için İtalya Merkez Bankası'nın gözetim faaliyetlerini belirlemek için 2004 yılından beri gerçekleşmektedir. Yine 2010 yılındaki kanun hükmünde kararname ile İtalya Merkez Bankası'nın tüm ödeme hizmetlerini kapsayacak şekilde ödeme sistemlerindeki yetkisi genişletilmiştir (BIS, 2012:39).

İtalya'da genel olarak temel ödeme araçlarının dağılımına bakıldığında 2010 yılı itibariyle dağılım; \% 30,65 oranında fon transferi, \% 14,81 oranında doğrudan ödeme, \% 48,46 oranında kartlar, \% 7,88 oranında çekler ile gerçekleşmiştir (European Central Bank, 2010; BIS, 2012:84).

\section{Kredi Kartı}

İtalya'da ilk kredi kartı 1958 yılında İtalya'da "Diners" tarafından verilmiştir. Diners'tan sonra 1968 ve 1971 yıllarında ise Amex BankAmericard tarafından kredi kartı çıkarılmıştır. Kredi kartı piyasası önceleri turistik amaçla İtalya'ya gelen yabancıların ve de İtalya'nın elit kişilerinin harcama işlemlerini yapmalarını sağlamalarına yönelik olduğundan kredi kartı kullanımı sınırlı kalmıştır. American Express 1980 'lerin ortalarına kadar İtalya'nın yaklaşık \% 45-50 pazar payı ile ana 
işlem operatörü olmuştur. 1986 yılında ise CartaSI'nin (Türkiye'deki BKM) kurulması ile kuruluş İtalya'da kart pazarına girmiştir. CartaSI ile birlikte Diners ve Amex BankAmericad kartı üye bankaların pazardaki güçlerinde zayıflama meydana gelmiş, banka hizmetlerini yeteri kadar sunamayan Amex ve Diners, çalışma metodlarında değişikliğe gitmiştir. American Express ve Diners kendisine rakip bankaların ilerisinde olabilmek için ve kendi kartlarının kabulünü artırmak için merchant fee'de (işletme/kullanıcı komisyonu) indirime gitmiştir. İtalya'da 1990'lı y1llara gelindiğinde ise mağazalarda kredi kartı kullanımda kitlesel bir artış yaşandığı gözlemlenmiştir. Bankalarla anlaşmaya giden yeni iştirakler ve kart kabul eden kuruluşların artmasıyla kart ihracında ve de kart kullanımında büyük artışlar yaşanmıştır (Cartedipagamento, 2012).

İtalya'da şuan dolaşımda olan 80 milyon ödeme kartı bulunmaktadır; bunların 33,6 milyonunu banka kartları ve 36 milyondan fazlasını ise kredi kartları oluşturmaktadır. Kredi kartlarıyla 2010 yılı içinde toplam 653 milyon adet işlem gerçekleşmiş ve 64,4 milyar euro toplam harcama yapılmıştır (Associazione Bancaria Italiana, 2011:1-2). Bununla birlikte artan kredi kartı kullanım miktarlarının nedenleri arasında gösterilebilecek ATM ve POS sayılarına bakıldığında da 2010 yılı sonu itibariyle İtalya'da 51.360 ATM ve 1,5 milyon POS bulunmaktadır (BIS, 2012:251).

\section{Internet}

İtalya'da online işlemler son yıllarda hızlı bir şekilde artmıştır. Online işlemlerin artmasına neden olan ve ağırlıklı olarak kullanılan online hizmetler; kredi kartı, ön ödemeli kartla yapılan alışverişler ve para transferleridir. Dolaşımdaki ön ödemeli kart sayısına bakıldığında bu durum ispatlanır niteliktedir. Ön ödemeli kart sayısı son 5 yılda hızla artmıştır. 2006'da 4,5 milyon olan sayı 2010'da 12,4 milyona ulaşmıştır (BIS, 2012:251). Kart Monitor dergisine göre İtalya'da İnternetten yapılan kartlı ödemelerdeki artış \% 18 oranındadır (BKM, 2012:13).

2012 Haziran Eylül dönemi ile bir önceki yıl aynı çeyrekte kartla online olarak gerçekleştirilen işlem sayısında \% 29'luk bir artış, tutar olarak da \% 23'lük bir artış olmuştur. Buna göre 2012 Eylül-Haziran döneminde 494 milyon euro değerinde işlem internet üzerinden gerçekleştirilmiştir (Associazione Bancaria Italiana, 2012:18).

\section{Elektronik Fon Transferi (EFT)}

İtalya bankalar arası ödemeler sistemi iki özel sistemi kapsamaktadır. Bunlardan biri büyük meblağlı ödemeler için olan RTGS 
(Real Time Gross Settlement) sistemi iken diğeri perakende işlemler için olan BI-COMP (Banca d'Italia Compensazione) sistemidir (BIS, 2012:252).

Fon transferlerinin işleyişinden İtalya Merkez Bankası sorumludur. İtalya Merkez Bankası'nın ödeme ve mutabakat sistemlerini sınıflandırarak kontrol mekanizmalarının yoğunluğunun buna göre ayarlaması ve düzenlenmesi, aynı zamanda gereken sinıflandırmayı yaparken ne tür özelliklere (ödeme sisteminin boyutuna, operasyonel özellikler ve katılımcı profilleri vb.) bakacağı konuları kanunlar ile açıkça düzenlenmiştir (Karpuz, 2012:87).

Verilere bakıldığında 2006 yılında 1,070 milyon adet olan işlem sayısı 2010 'da 1,227 milyon adete ulaşmıştır. Yine 2006 'da 6,222 milyar euro olan işlem hacmi, 2010'da 7,938 milyar euro olarak gerçekleşmiştir (BIS, 2012:248).

\section{Akıllı (Smart) Kart-Elektronik Para}

Elektronik paranın tanımı Avrupa Birliği'nin ilgili düzenlemelerinde; elektronik para ihraç eden kuruluş tarafından kabul ettiği fon karşılığı çıkartılan, elektronik olarak saklanan ve hamili tarafından ödeme işlemini gerçekleştirmek için kullanılan parasal değer olarak ifade edilmektedir. Buradaki önemli nokta, parasal bir değerin elektronik para olarak değerlendirilmesi için gerekli bir diğer özellik de söz konusu parasal değerin elektronik parayı ihraç eden kuruluş dışındaki gerçek ve tüzel kişiler tarafından da ödeme aracı olarak kabul edilmesi gerekmesidir (Karpuz, 2012:145).

Elektronik para konusunda toplam işlem miktarının çok az olmasından dolayı akıllı kart kullanımı verileri konusunda rakam belirtilememektedir. Bu konuda tek istisna Singapur'dur. Singapur'da nakit dışı ödeme araçları arasında elektronik paranın toplam işlem miktarı arasındaki kullanım oranı \% 74 dolaylarındadır (Kirdaban, 2005:41).

\section{Diğerleri}

Cartasi Mobile: Portal, kullanıcılarına mobil cihazlardan erişim imkânı sağlayarak alışveriş yapmalarına olanak tanımaktadır. Sistem, cep telefonunun sunduğu imkânlardan daha çok fayda sağlayabilmek için bilgi servislerinin ve ödeme altyapısının geliştirilmesiyle kabul gören bir ödeme platformu olarak hizmet vermektedir (Cartasi, 2012).

Paypal: Sistem İtalya'da sıkça kullanılan elektronik ödeme araçlarındandır. Türkiye'de olduğu gibi İtalya'da da farklı kuruluşlar değişik isimlerde bu hizmeti müşterilerine sunmaktadır. Bank Sella tarafından sunulan GestPay sistemi, Cartasi tarafından sunulan Xpay, Iwbank tarafından sunulan IwSmile, IntesaSanpaolo'nun Setefi sistemi 
bunlardandır. Bu sistemlerden en çok kullanılanı da GestPay (\% 44) ve Xpay (\% 27)'dir (Casaleggio, 2012:29).

\section{Sonuç}

Son yıllarda banka kartları ve kredi kartlarının kullanımı rakamlarda da görüldüğü üzere gittikçe artmıştır. POS ve ATM'lerin sayılarının artması, farklı ödeme imkanlarının sunulması ve alışveriş alışkanlıklarının değişmesi artan kart kullanımının nedenleri arasında gösterilebilir. Bu anlamda Türkiye ve İtalya arasında bir karşılaştırma olduğunda Türkiye'deki kart sayısının İtalya'daki kart sayısına göre daha fazla olduğu görülmektedir. Her iki ülkenin nüfusuna ve kart sayısına bakıldığında Türkiye'de nüfus yaklaşık 74 milyon iken kart sayısı 53 milyonun üzerindedir. İtalya'da ise nüfus 61 milyon civarındadır ve kredi kartı sayısı 36 milyon civarındadır. Harcama tutarı olarak bakıldığında ise Türkiye'de neredeyse İtalya' daki işlem tutarından iki kat daha fazla tutarda kredi kartı ile harcama yapılmaktadır. Türkiye'de kredi kartı ile alışverişlerde taksit imkanının da olması ve Türkiye'deki insanların taksitli alışverişi yoğun olarak tercih etmesi Türkiye'deki yoğun kart kullanımının ve aşırı harcama tutarının en önemli nedenlerindendir.

İnternet üzerinden gerçekleştirilen kartlı ödemelere bakıldığında da İtalya'da internetten yapılan kartlı ödemelerdeki artış \% 18 civarında bir artış göstermekteyken, Türkiye'deki artış \% 50'dir. Bu durum Türkiye'de kart sayısının fazlalığının yanında kartların online olarak da daha fazla kullanıldığını göstermektedir. İnternetten yapılan kartlı ödemelerde Avrupa ülkeleriyle karşılaştırma yapıldığında, Türkiye'nin büyüme grafiği \% 50'yi bulurken İtalya'nın büyüme grafiği \% 18'de kalmıştır. Bankalararası Kart Merkezi'nin verileri incelendiğinde, Türkiye bu oranla sadece İtalya'yı geçmemiş aynı zamanda Fransa, $\mathrm{ABD}$, İngiltere gibi ülkeleri de geride bırakmışır. Dolayısıyla teknolojinin ödeme sistemlerine yansıyarak tüketicilere farklı elektronik ödeme imkanları sunması İtalya ile birlikte diğer ülkelerdeki kartlı ödeme sistemlerindeki artışın nedenleri arasındadır; ancak belirtildiği üzere Türkiye'de kredi kartlarının taksit imkanı sunması ve Türkiye'deki alışveriş alışkanlıkları ister sanal ister fiziki ortamda Türkiye'deki kartlı ödemelerindeki yüksek artışın an önemli nedenlerindendir.

Ödeme sistemlerinin denetimi, işleyişi ve diğer düzenlemeler konusunda İtalya ve Türkiye'deki yetkili otorite Merkez Bankası'dır. Bu anlamda hem İtalya Merkez Bankası hem Türkiye Cumhuriyet Merkez Bankası gözetim ve denetim faaliyetlerini etkin bir şekilde gerçekleştirebilmeleri için gerekli yasal altyapılarla desteklenmiştir. Güncel 
gelişmeler ve elektronik ödeme sistemlerinde ortaya çıan yenilikler Merkez Bankaları'nın altyapılarını bu yeniliklere gerçekleştirme uydurma zorunluluğunu beraberinde getirmiştir. Kredi kartlarıyla ister online veya ister POS'tan yapılan harcamaların artması ekonomideki harcamaların tespit edilebilmesi anlamına geldiğinden etkin bir denetim ve gözetim mekanizmasıyla harcamalar kayıt altına alınarak ülkelerde kayıtdışı ekonomi azalacaktır.

\section{Kaynakça}

Assocıazıone Bancarıa Italıana; (2011), "Banche: Abi, in Italia 80 Milioni di Carte di Pagamento", Roma, 3 Novembre, http://www.abieventi.it/public/files/cs-abi-x-news/03-11-Carte.pdf, 07.01.2013.

Associazıone Bancarıa Italıana; (2012), "I sistemi di pagamento nella realtà italiana", Settembre, http://www.abi.it/DOC Mercati/Sistemipagamento/RilevazioneABI/Rilevazione-

ABI/sist pag set2012 dati\%20 set2012\%20per\%20sito.pdf, 09.01.2013.

Bank For Internatıonal Settlements (BIS); (2012), Payment, Clearing and Settlement Systems in the CPSS Countries, Committee on Payment and Settlement Systems, Vol: 2, November, 2012.

Bankalararası Kart Merkezi (BKM); (1997), "Kredi Kartlarının Tarihçesi", Pano Dergisi, Sayı:2, Kasım.

Bankalararası Kart Merkezi; (2000), “Chip Kart”, Pano Dergisi, Sayı:7, Haziran.

Bankalararası Kart Merkezi; (2012a), "Bankalararası Kart Merkezi/Kuruluş", http://www.bkm.com.tr/kurulus.aspx, 30.12.2012.

Bankalararası Kart Merkezi; (2012b), Yerli Kredi Kartlarının Yurtiçi Kullanımı,

http://www.bkm.com.tr/istatistik/kredikarti yurtici issuer islemleri. asp, 20.12.2012.

Bankalararası Kart Merkezi; (2012c), “Kredi kartı sayısı 55 milyona koşuyor", Kredi Kartları Kullanım Alışkanlıkları Araştırması, Kart Monitör Dergisi, Yıl: 2012.

Bankalararası Kart Merkezi Express; (2013), “BKM Ekspres Nedir?" https://www.bkmexpress.com.tr/BKMExpress/headerLinks/info.bk m, 04.01.2013. 
Cartedipagamento, (2012); "Storia Della Carta di Credito", http://www.cartedipagamento.com/storia della carta di credito.ht m, 30.12.2012.

Cartasi;

Profolio, http://www.cartasi.it/download/comunicati/CARTELLA STAMPA GRUPPO CARTASI.pdf, 25.12.2012.

Casaleggio Associatı, (2012); E-Commerce in Italia 2012, Report Aprile.

European Central Bank (ECB); (2010), The Payment System-Payments, Securities and Derivatives, and the Role of The Eurosystem, ECB Report, Editor: Tom Kokkola, 2010.

İşbankası; (2012), Akıllı Kartlar-Ulaşım ve Üniversite Uygulamaları, http://www.isbank.com.tr/content/TR/Kartlar/Akilli Kartlar/Univers ite Uygulamalari/Kocaeli Universitesi-781-643.aspx, 25.12.2012.

Karpuz, Emre; (2012), Ödeme Sistemleri ve Araçlarının Artan Kullanımı: Kredi Kartı Kullanımının Para Politikası Etkinliğine Etkisi, TCMB Uzman Yeterlilik Tezi, Nisan, Ankara.

Kirdaban, M.İbrahim; (2005), Ödeme Sistemlerindeki Gelişmeler ve Ödeme Sitemlerinin Finansal Sistem İstikrarı Üzerindeki Etkileri, TCMB Uzman Yeterlilik Tezi, Şubat, Ankara.

Nagasubramanian R. and S.P.RAJAGOPALAN; (2012), “Online Payment Innovation in Split Tender Payment", International Journal of Computer Applications, Volume:55, No:10, October 2012, pp.35-42.

Özmen, Şule; (2012), Ağ Ekonomisinde Yeni Ticaret Yolu: e-ticaret, İstanbul Üniversitesi Bilgi Üniversitesi Yayınları, İstanbul.

Türkiye Bankalar Birliği (TBB); (2012), İstatistiki Raporlar, http://www.tbb.org.tr/tr/banka-ve-sektor-bilgileri/istatistikiraporlar/59, 25.12.2012.

Türkiye Cumhuriyet Merkez Bankası; (2013a), “Ödeme Sistemlerinin Kapsamı ve Önemi", http://www.tcmb.gov.tr/yeni/osi/I1Tr.htm,02.01.2013.

Türkiye Cumhuriyet Merkez Bankası; (2013b), “TCMB'nin Ödeme Sistemlerindeki Hedef ve Politikaları", http://www.tcmb.gov.tr/yeni/osi/I3Tr.htm, 02.01.2013.

Türkiye Cumhuriyet Merkez Bankasi; (2012a), “EFT-EMKT Sisteminden Geçen Günlük Mesaj ve Para Hacmi", http://www.tcmb.gov.tr/basin/3.40.pdf, 25.12.2012. 
Sosyal Bilimler Dergisi 37

Türkiye Cumhuriyet Merkez Bankasi; (2012b), EFT ve EMKT, http://eft.tcmb.gov.tr/EFT-tanitim.htm, 25.12.2012.

Türkiye Cumhuriyet Merkez Bankası; (2006), Elektronik Fon ve Menkul Kıymet Transfer ve Mutabakat Sistemi Tanıtım Kitapçı̆̆ı, Türkiye Cumhuriyet Merkez Bankası Banknot Matbaası Genel Müdürlüğü, Haziran. 